\title{
Fibroepothelial polyp of the glans penis due to pad use for urinary incontinence
}

\author{
Şükrü Kumsar, MD; Hasan Salih Sağlam, MD; Osman Köse, MD; Salih Budak, MD; Oztuğ Adsan, MD \\ *Sakarya Education and Training Hospital, Sakarya, Turkey; 'Sakarya University Medical Faculty, Department of Urology, Sakarya, Turkey
}

Cite as: Can Urol Assoc J 2013;7:E257-9. hittp://dx.doi.org/10.5489/cuai.543

\section{Abstract}

A 78-year-old man was admitted to our urology polyclinic with painless penile mass. The lesion was $3.5 \mathrm{~cm}$ in size on the ventral aspect of the penis. He had been using a pad for urinary incontinance for 10 months and said that the lesion had been increasing in size for past 3 months. He underwent a wide local excision under local anesthesia. The histopathologic diagnosis was fibroepithelial polyp. A fibroepithelial polyp of the penis is very rare and strongly linked to long-term condom catheter use. We present a case of fibroepithelial polyp of the glans which is not associated with condom catheter use.

\section{Introduction}

A fibroepithelial polyp of the penis is very rare and strongly linked to long-term condom catheter use. ${ }^{1}$ Fibroepithelial polyps of the penis have only recently been described and, to our knowledge, only 1 series ( 7 cases) and 4 case reports have been reported. ${ }^{2}$ Most patients have a long-term history of condom catheter use. Only 1 patient in a series by Fetsch and colleagues developed a similar lesion with longstanding neglected paraphimosis. ${ }^{3}$

Recently Peña and Prada described a rare case of lymphedematous fibroe pithelial polyp of the glans penis not associated with long-term condom catheter use; the patient had a 4-month history of lower urinary tract symptoms. ${ }^{4}$ Moreover, Tsai and colleagues described a fibroepithelial polyp of the glans penis also not associated with long-term condom catheter use in a man who allegedly practiced genital hanging kung fu for more than 10 years. ${ }^{5}$

We present a case of fibroepithelial polyp of the glans penis which is not associated with condom catheter use.

\section{Case report}

A 78-year-old man was admitted to our urology polyclinic with painless penile mass. He had obstructive urinary symptoms for 5 years and urgency/urge incontinence for 1 year, but he received no medication for his symptoms. He had $20 \mathrm{~mL}$ of post-void residual urine on suprapubic transvesical ultrasonography. He had been using a pad for urinary incontinance for 10 months, but he said the lesion had been increasing in size for past 3 months. A polypoid shaped mass was found on the glans penis, primarily involving the ventral surface of the penis near the urethral meatus, with no urethral involvement (Fig. 1). The lesion was $3.5 \mathrm{~cm}$ in size on the ventral aspect of the penis on the frenulum zone. It was warty, solid and multilobulated mass. He underwent a wide local excision under local anesthesia. There was no communication with the urethra. The excised mass was $3.5 \times 3 \times 2.5 \mathrm{~cm}$. The penile skin was closed with 3-0 rapid vicryl sutures.

Histologically the lesion had a polypoid configuration. The overlying keratinizing squamous epithelium showed acanthosis and hyperkeratosis without koilocytic change. The stroma was notably edematous, with telangiectasia of pre-existing vessels, and there were focal small vessel proliferations (Fig. 2). Immunhistochemically, the stromal cells had limited immunoreactivity for alfa-smooth muscle actin, and no reactivity for s-100 protein or CD34. The histopathologic diagnosis was fibroepithelial polyp.

Alpha blocker and anticholinergic combination therapy was started and he had follow-up visits at 3 and 6 months postoperatively which showed normal findings and no recurrence at the glans penis (Fig. 3). His obstructive and urgency/ urge incontinance symptoms also disappeared.

\section{Discussion}

Fibroepithelial polyps are rare; however, they are the most common benign mesodermal tumours of the urinary tract. 


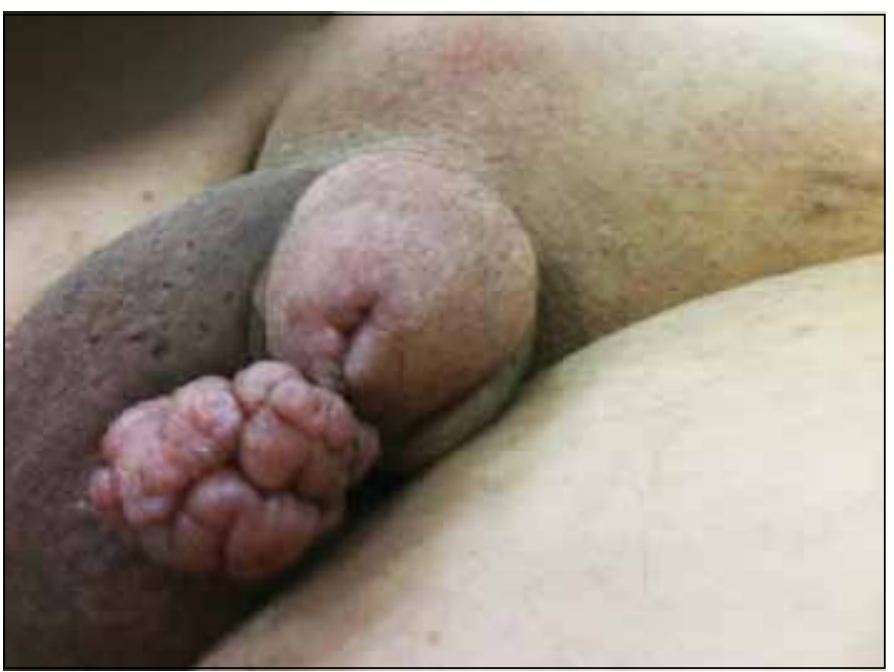

Fig. 1. Polypoid shaped mass involving the ventral surface of the penis.

They are rarely found in the urinary tract and more frequently found in the ureter and renal pelvis; they rarely ocur in the posterior urethra or bladder. ${ }^{6}$ Fibroepithelial polyps of the glans penis differ from those involving the urinary tract with regard to their pathogenesis, shape, size and histologic features.

Clinically, the differential diagnosis should include acrochordon, condyloma acuminatum and squamous or urot-

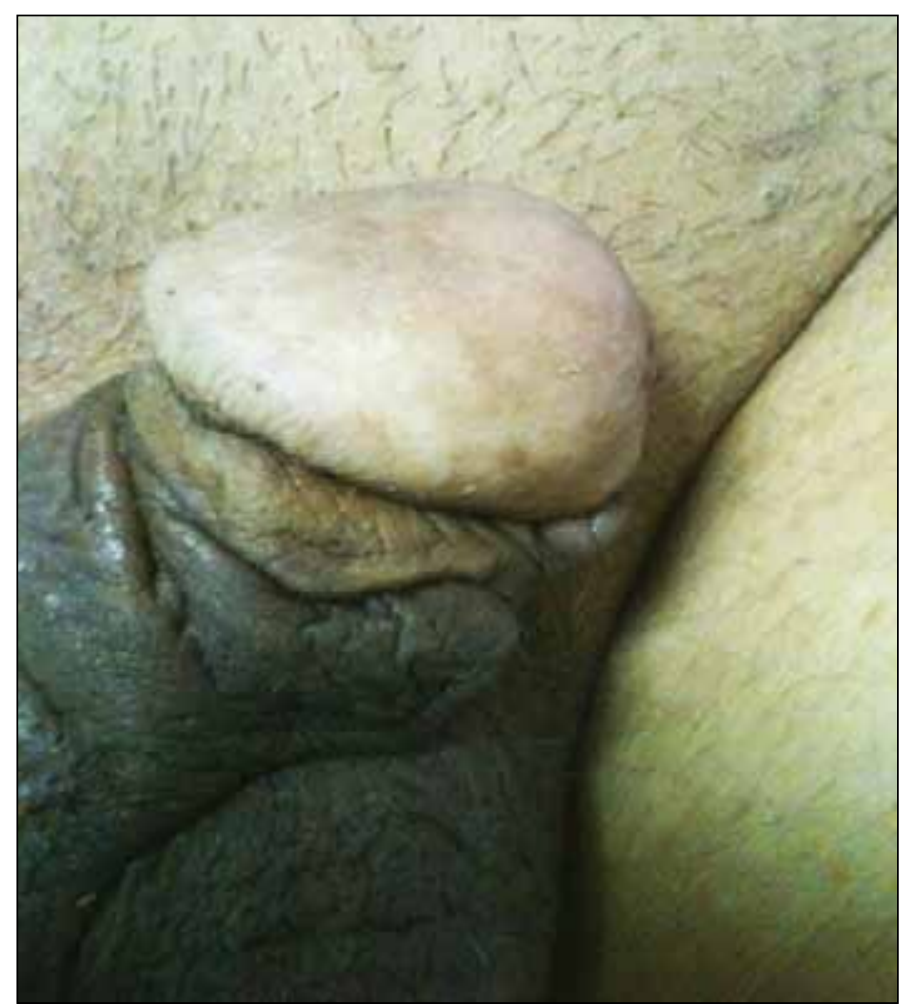

Fig. 3. Lateral aspect of the penis at 6 -month control.

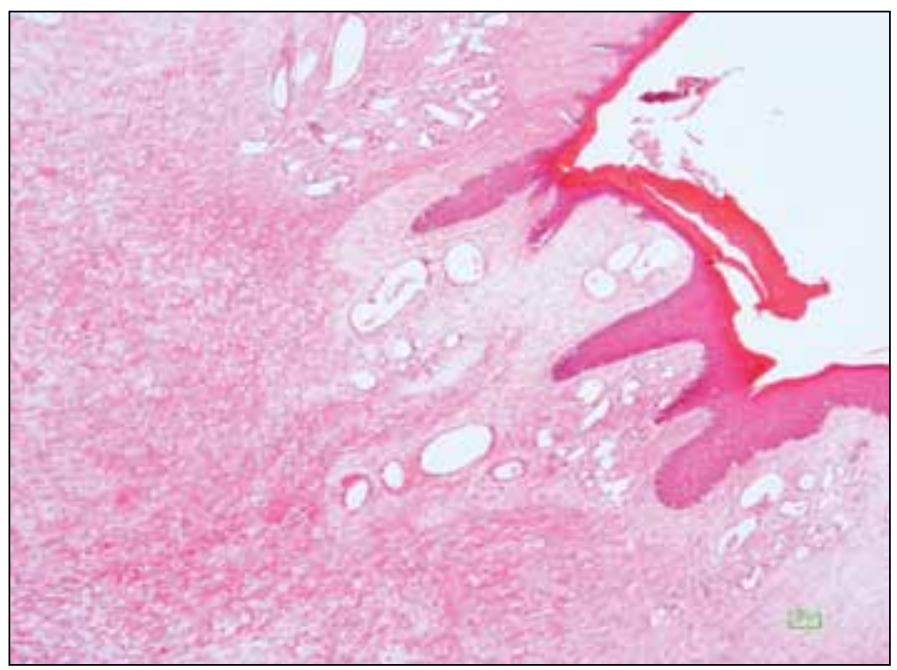

Fig. 2. A polyp with squamous epithelium and subepithelial loose connective tissue has telangiectatic vessels and mild small vessel proliferation.

helial carcinoma; a differential diagnosis is posssible with histopathological analysis. ${ }^{2}$

Since fibroepithelial polyps of the glans penis were first reported by Fetsch and colleagues in 2004, ${ }^{3}$ other reports have surfaced linking that lesion with long-term condom catheter use in quadriplegic or paraplegic patients.

Fibroepithelial polyps's presence on the penis is reported infrequently. Our patient had a mass on the ventral surface of the penis, near the urethral meatus. This is compatible with reports in the literature. The median age of patients with such polyps was 40 , but in our case the patient was 78 years old. ${ }^{6}$

Although the pathogenesis of this process is unclear, polyps likely develop due to chronic irritation because of a urine leak around an ill-fitting device, a maceration or an ulceration. $^{?}$

\section{Conclusion}

In our case a strong visible link with condom catheter use suggests that the basic process is probably a reactive hyperplasia, rather than a true neoplasm. Our patient had not used a condom catheter, had a urinary leak and used a pad for 1 year. In our case, urinary incontinence and chronic irritation are likely causes. Urologists and pathologists should be mindful of these causes in patients with polyps, regardless of whether they use a condom catheter or pads for urinary incontinence. Resection of the polyp is usually curative. Many patients use condom catheters and pads for urinary incontinence, but penile fibro epithelialpolyps are not seen. More reports are needed to elucidate the etiopathogenesis.

Competing interests: None declared. 
This paper has been peer-reviewed.

\section{References}

1. Turgut M, Yenilmez A, Can C, et al. Fibroepithelial polyp of glans penis. Urology 2005;65:593. http:// dx.doi.org/10.1016/i.urology.2004.09.071

2. Mason SE, Viliers PD, Andea AA. Lymphedematous fibroepithelial polyps of the penis associated with long-term condom catheter use: case report and review of the literature. J Cut Pathol 2009;36:906-9.

3. Fetsch JF, Davis $\mathrm{CJ} \mathrm{Jr}$, Hallman JR, et al. Lymphedematous fibroepithelial polyps of the glans penis and prepuce: A clinicopathologic study of 7 cases demonstrating a strong association with chronic condom catheter use. Hum Pathol 2004;35:190-5. http://dx.doi.org/10.1016/i.humpath.2003.08.021
4. Pena KB, Parada D. Lymphedematous fibroepithelial polyp of the glans penis non-associated with condom catheter use. APMIS 2008;1 16:215-8.

5. Tsai TF, Hung $\mathrm{CS}$, Hsiao $\mathrm{CH}$. Fibroepithelial polyp of glans penis in a man who practiced genital hanging kung fu. J Am Acad Dermatol 2008;59:S35-7. hitp://dx.doi.org/10.1016/i.jaad.2007.07.048

6. Williams TR, Wagner BJ, Corse WR, et al. Fibroepithelial polyps of the urinary tract. Abdom Imaging 2002;27:217-21. http://dx.doi.org/10.1007/s00261-001-0066-z

7. Kim YD, Lee MH, Kim MJ, et al. Giant fibroepithelial polyp of the glans penis. Korean J Urol 2009;50:61921. http://dx.doi.org/10.4111/kju.2009.50.6.619

Correspondence: Dr. Şükrü Kumsar, Sakarya Education and Training Hospital, Uroloji Kliniği, Sakarya, Turkey; fax: 90264275 91 92; drkumsar@yahoo.com 